\title{
27. TETRAPYRROLE PIGMENTS FROM BERMUDA RISE: DSDP LEG 43
}

\author{
S. E. Palmer,' W. Y. Huang, and E. W. Baker,' Northeast Louisiana University, Department of Chemistry, \\ Monroe, Louisiana
}

\section{INTRODUCTION}

Coring during four recently completed DSDP legs in the Atlantic, including the one reported here, has recovered Lower and Upper Cretaceous sediments rich in organic carbon. Geochemical studies of samples from these legs have confirmed and extended ideas concerning the diagenesis of chlorophyll in marine environments.

The transition from free-base porphyrins to metalloporphyrins (nickel and vanadyl) was clearly illustrated in Lower Cretaccous sediments collected during Leg 40 from the Cape and Angola basins at a depth of burial of 1000 to 1190 meters (Baker et al., 1978a). Even later diagenetic products, resembling the petroporphyrins, were present in Leg 41 Upper Cretaceous sediments ( 940 to $980 \mathrm{~m}$ ) of the Cape Verde Rise (Baker et al., 1978c). The molecular weight distributions of these pigments, transalkylated nickel and vanadyl porphyrins, demonstrated the influence of relatively high temperatures imposed by igneous intrusive activity.

Intermediate diagenetic products (chlorins, free-base porphyrins, and nickel porphyrins) were found in Lower to Upper Cretaceous sediments collected during Leg 41 at 440 to 880 meters, and during Leg 44 in the Lower Cretaceous of the Blake-Bahama Basin at 690 to 960 meters (Baker et al., 1978c, 1978d).

Analysis of each of the above suites of Cretaceous sediments resulted in abundant data concerning a rather specific state of chlorophyll diagenesis. In contrast to these previous studies, extracts of Leg 43 samples contained intermediate diagenetic products and porphyrins distinctly representative of a later stage, that of dealkylation. In this study, Cretaceous sediment samples from Site 387 were found to contain primarily chlorins and nickel porphyrins not unlike those found in Leg 44 Cretaceous black shales and may represent samples of the same shale unit. However, late diagenetic products, dealkylated nickel porphyrins, were recovered from black shales in Site 386. One samp'e, Core 386-43, contained free-base and vanadyl porphyrins in addition to chlorins and nickel porphyrins. The youngest samples (Pleistocene to Miocene) contained only chlorins, while the most deeply buried Cretaceous sediments contained only nickel porphyrins. Data are presented in Table 1.

\footnotetext{
${ }^{1}$ Present Address: Florida Atlantic University, Dept. of Geology, Boca Raton, Florida.

${ }^{2}$ University of New Orleans, Biol. Sci. Dept., New Orleans, Louisiana.

${ }^{3}$ Florida Atlantic University, College of Science, Boca Raton,
}

\section{EXPERIMENTAL}

The 16 core samples analyzed (100 grams each) in this study were stored frozen. Mixtures of acetone:methanol (9:1) were used for ball mill extraction of pigments. Crude extracts containing sufficient amounts of pigment ( $1 \mu \mathrm{g}$ or more) were chromatographed over Sephadex LH-20 with THF. (Several crude extracts had one $\mu \mathrm{g}$, or less total pigment, typically chlorin plus nickel porphyrin; the pigments in these samples were separated by $\mathrm{HCl}$-ether partition). Chlorins and free-base prophyrins were isolated from the crude extract and purified by ether$\mathrm{HCl}$ partition after diazomethane derivatization. The metalloporphyrins, which remained in the ether partition layer, were thus separated from the chlorins and free-base porphyrins. The nickel and vanadyl porphrins were then separated and purified by chromatography over Grade III Alumina with cyclohexane:benzene (50:50) and benzene:dichloroethane (50:50), respectively.

Each step of sample work-up was monitored by UVvisible spectrophotometry using a Beckman Acta CIII scanning spectrophotometer. Mass spectra of porphyrins were recorded using the solid probe injection system of a DuPont 491-BR mass spectrometer. The source temperature was held at $275^{\circ} \mathrm{C}$ to $285^{\circ} \mathrm{C}$ while the probe temperature was increased in $5^{\circ}$ increments, expelling the more volatile nonporphyrin compounds, until the desired probe temperature was reached (generally $240^{\circ} \mathrm{C}$ ). At this point, temperature was held constant and the mass spectrum recorded. Some of the nickel porphyrin isolates which did not have a sufficiently high degree of volatility required use of the inverted probe tip method (initially described by Baker, Palmer, and Parrish, 1976).

\section{RESULTS}

\section{Distribution With Respect to Depth of Burial and Age}

Age and depth of burial are important factors in the distribution of pigments isolated from Leg 43 cores. The shallow, geologically younger sediments of Site 382 contained only early diagenetic chlorins. Site 387 sediments, collected at 263 to 787 meters, range from Eocene through Lower Cretaceous. Small amounts of chlorins $(0.004$ to $0.55 \mu \mathrm{g} / \mathrm{g})$ and nickel porphyrins $(0.01$ to $0.17 \mu \mathrm{g} / \mathrm{g})$, representative of an intermediate diagenetic stage, were found in all samples from this site.

The deepest core samples in this study are from Site 386 (Core Sections 60-5 and 63-1) and were collected 
TABLE 1

Sample and Pigment Data Obtained From DSDP Leg 43 Cores



${ }^{a}$ Data obtained from Leg 43 Summary

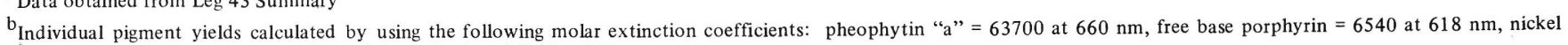
porphyrin $=34820$ at $550 \mathrm{~nm}$, and vanadyl porphyrin $=26140$ at $570 \mathrm{~nm}$.

between 915 and 937 meters below the sea floor. Relatively high yields of nickel porphyrins were obtained. As discussed later, these particular pigments are mass spectrometrically similar to those recovered from previously studied Cretaceous sediments but are markedly different from those collected at shallower depths.

In the Upper Cretaceous sediment of Core 386-43, a large amount of extractable organic matter, corresponding to high organic carbon content ( $7.69 \%)$, was present. As could be expected, this sample, collected at 741 meters depth, contained chlorins and nickel porphyrins similar to those found in Site 387 sediments.

Also present were free-base and vanadyl porphyrins. The occurrence of these classes of pigments together is surprising. Free-base porphyrins have previously been found in association with chlorins such as those reported here. Vanadyl porphyrins have been found associated with nickel porphyrins and free-base porphyrins, but do not generally occur with chlorins (see Discussion). Ten and twenty-five meters below Core $386-43$, pigment concentrations drop to $0.01 \mu \mathrm{g} / \mathrm{g}$ of sediment. Changes in pigment concentrations and characteristics in these cores $(386-43,-44,-45)$ may be influenced by the inconsistencies in lithology.

\section{Characterization of Chlorins}

The two methods used for isolation of chlorin fractions (Sephadex LH-20 chromatography and $\mathrm{HCl}$ ether partition) also have qualitative value. Chlorins from the Pleistocene of core Section 382-1-4 were isolated in an early-running fraction from Sephadex LH-20 and extracted into 20 percent $\mathrm{HCl}$. These two data, coupled with the UV-visible spectrum, are indicative of pheophtytin-like chlorins. In contrast, the chlorin fraction isolated from Upper Cretaceous Core 386-43 co-chromatographed with the free-base and metalloporphyrins and was extractable into 10 percent $\mathrm{HCl}$. In the UV-visible spectrum, the red band was shifted to lower wavelengths $(657-659 \mathrm{~nm})$ for all the Cretaceous chlorin samples.

Increased purity of chlorin fractions is generally achieved through multiple $\mathrm{HCl}$ extractions. When this method was applied to the chlorin fraction from Core 386-43, changes in the UV-visible spectrum were observed. The red band initially appeared at $659 \mathrm{~nm}$; as isolation progressed, a second red band appeared at $642 \mathrm{~nm}$. After completion of the third $\mathrm{HCl}$ extraction, the $642 \mathrm{~nm}$ band predominated and peaks at 500 and $619 \mathrm{~nm}$, representative of free-base porphyrin, appeared. In addition, the Soret band narrowed and moved from 410 to $403 \mathrm{~nm}$. These changes in the spectrum, coupled with the low $\mathrm{HCl}$ number, suggest that chlorins of this type are diagenetically very close to the chlorin-porphyrin transition. Ease of artifact formation makes study of this particular chlorin fraction difficult.

\section{Mass Spectrometric Analyses of Porphyrins}

Free-base porphyrins: The molecular weight distribution for free-base porphyrins isolated from Core 386-43 were similar to those reported previously (Baker et al., 1977a, c). These data are reported in Table 2. Five members of a DPEP homologous series were observed, with m/e 476, the nominal molecular weight of DPEP, predominating. Small mass spectral peaks were also observed at $\mathrm{m} / \mathrm{e} 478,450,436$, and 422. Pending further study, these may be free-base porphyrins of the etio or phyllo series (both being 310 
TABLE 2

Mass Spectrometric Data of Free Base and Metalloporphyrins From Leg 43 Sites 386 and 387

\begin{tabular}{|c|c|c|c|c|c|c|c|c|c|c|c|}
\hline & & & & & rbon & Numbe & & & & & \\
\hline & 33 & 32 & 31 & 30 & 29 & 28 & 27 & 26 & 25 & 24 & \\
\hline $386-43$ & & & & & & & & & & & \\
\hline Free-base porphyrin & & 476 & 462 & 449 & 434 & 420 & & & & & DPEP series \\
\hline Nickel porphyrin & & 537 & 523 & $\begin{array}{r}15 \\
509\end{array}$ & 7 & 3 & & & & & Unidentified series \\
\hline & & $\begin{array}{l}100 \\
539\end{array}$ & $\begin{array}{r}47 \\
525\end{array}$ & $\begin{array}{r}25 \\
511\end{array}$ & 497 & 483 & & & & & Unidentified series \\
\hline & & 15 & 10 & 16 & 22 & 22 & & & & & \\
\hline & & 532 & 518 & 504 & 490 & 476 & & & & & DPEP series \\
\hline & & 28 & 28 & 38 & 31 & 22 & & & & & \\
\hline & & 534 & 520 & 506 & 492 & 478 & 464 & 450 & & & etio series \\
\hline & & 5 & 5 & 11 & 16 & 23 & 28 & 50 & & & \\
\hline Vanadyl porphyrin & & 541 & 527 & 513 & 499 & & & & & & DPEP series \\
\hline & & 87 & 100 & 70 & 43 & & & & & & \\
\hline $386-60$ & & & & & & & & & & & \\
\hline Nickel porphyrin & 546 & 532 & 518 & 504 & 490 & 476 & 462 & 448 & 434 & & DPEP series \\
\hline & 20 & 51 & 50 & 59 & 43 & 30 & 18 & 10 & 4 & & \\
\hline & 548 & 534 & 520 & 506 & 492 & 478 & 464 & 450 & 436 & & etio series \\
\hline & 2 & 16 & 72 & 100 & 96 & 81 & 41 & 23 & 9 & & \\
\hline $386-63$ & & & & & & & & & & & \\
\hline Nickel porphyrin & 546 & 532 & 518 & 504 & 490 & 476 & 462 & 448 & 434 & & DPEP series \\
\hline & 20 & 51 & 50 & 59 & 43 & 30 & 18 & 10 & 4 & & \\
\hline & 548 & 534 & 520 & 506 & 492 & 478 & 464 & 450 & 436 & 422 & etio series \\
\hline & 2 & 23 & 41 & 82 & 85 & 100 & 66 & 43 & 21 & 10 & \\
\hline $387-16$ & & & & & & & & & & & \\
\hline Nickel porphyrin & & & & & 497 & 483 & 469 & 455 & 441 & & Unidentified series \\
\hline & & & & & 41 & 81 & 86 & 100 & 86 & & \\
\hline & & & & 504 & 490 & 476 & & & & & DPEP series \\
\hline & & & & 92 & 35 & 32 & & & & & \\
\hline & & & & 506 & 492 & 478 & 464 & 450 & 436 & & etio series \\
\hline & & & & 16 & 30 & 82 & 68 & 73 & 49 & & \\
\hline $387-26$ & & & & & & & & & & & \\
\hline Nickel porphyrin & & & & & 497 & 483 & 469 & 455 & & & Unidentified series \\
\hline & & & & 504 & $\begin{array}{r}39 \\
490\end{array}$ & $\begin{array}{r}53 \\
476\end{array}$ & & & & & DPEP series \\
\hline & & & & 100 & 80 & 37 & & & & & \\
\hline & & & & & 492 & 478 & 464 & 450 & & & etio series \\
\hline & & & & & 19 & 88 & 78 & 61 & & & \\
\hline $387-35$ & & & & & & & & & & & \\
\hline Nickel porphyrin & & & & 511 & 497 & 483 & 469 & 455 & 441 & & Unidentified series \\
\hline & & & & 50 & $\begin{array}{r}54 \\
492\end{array}$ & $\begin{array}{r}79 \\
478\end{array}$ & $\begin{array}{r}75 \\
464\end{array}$ & $\begin{array}{r}79 \\
450\end{array}$ & $\begin{array}{r}67 \\
436\end{array}$ & & etio series \\
\hline & & & & & 50 & 88 & 79 & 100 & 75 & & \\
\hline $387-37$ & & & & & & & & & & & \\
\hline Nickel porphyrin & & 537 & 523 & & & & & & & & Unidentified series \\
\hline & & 40 & 40 & & & & & & & & \\
\hline & & 539 & 525 & 511 & 497 & 483 & & & & & Unidentified series \\
\hline & & 20 & 25 & 70 & 60 & 60 & & & & & \\
\hline & & 532 & 518 & 504 & .590 & & & & & & DPEP series \\
\hline & & 30 & 40 & 55 & 40 & & & & & & \\
\hline & & & 520 & 506 & 492 & 478 & 464 & & & & etio series \\
\hline & & & 20 & 39 & 55 & 100 & 70 & & & & \\
\hline $387-49$ & & & & & & & & & & & \\
\hline Nickel porphyrin & & 537 & 523 & 509 & & & & & & & Unidentified series \\
\hline & & 43 & 36 & 29 & & & & & & & \\
\hline & & & & 511 & & & & & & & Unidentified series \\
\hline & & & & 15 & & & & & & & \\
\hline & & 532 & 518 & 504 & & & & & & & DPEP series \\
\hline & & 36 & 41 & 50 & & & & & & & \\
\hline & & & 520 & 506 & 492 & 478 & 464 & 450 & 436 & & etio series \\
\hline & & & 36 & 57 & 64 & 100 & 71 & 93 & 57 & & \\
\hline
\end{tabular}

Note: Data are presented as normalized peak intensities for free-base, vanadyl porphyrins, and nickel porphyrins of the DPEP series. Correction for $\mathrm{Ni}^{60}$ isotope contribution to the etio series from corresponding DPEP series was made. This same correction procedure was used for normalization of the two unknown metalloporphyrin series. 
$+14 n$ ). In support of this, a slight divergence from the typical DPEP type visible spectrum was found: band II was shifted from 562 to $571 \mathrm{~nm}$.

Vanadyl porphyrins: Four members of a homologous series of DPEP-type porphyrins were mass spectrometrically observed in the vanadyl porphyrin fraction from Core 386-43. Although previously recorded spectra (Leg 40) contained three to four DPEP homologs, the $\mathrm{m} / \mathrm{e} 541$ (molecular weight of vanadyl DPEP) always made the largest contribution. In this case, the next lower homolog, representative of a $\mathrm{C}_{31}$ DPEP-type porphyrin, predominated.

Nickel porphyrins: The molecular weight distributions of nickel porphyrins from Cores 386-60 and -63 form a nearly symmetrical envelope (Table 2 ). In both samples, the etio series predominated with DPEP/etio ratios of 0.6 . Nine to ten DPEP and etio homologs were present, with $C_{28}$ to $C_{30}$ (m/e 478, 492, 506) porphyrins predominating. In contrast to these highly dealkylated series, the $\mathrm{C}_{32}$ and $\mathrm{C}_{31}$ members (m/e 532, 518 ) of the DPEP series were previously reported as being major components, resulting in a "truncated" molecular weight distribution. Only two other cases where extreme dealkylation of both series and predominance of the etio over the DPEP series have been reported. The first case was a Leg 38 Eocene sample (346-15) and the second was the thermally stressed Leg 41 Cretaceous samples (368-63-2).

Small amounts of $\mathrm{C}_{33}$ porphyrins of the DPEP and etio series were present. Again, such values (m/e 546 and greater), which are indicative of the addition of alkyl substituents through transalkylation, have been previously observed only as minor components of the total nickel porphyrin mixture.

Mass spectrometric data of nickel porphyrins isolated from Core 386-56 were not as easily interpretable as for 386-60 and -63 , and these data are not reported in Table 2. However, a dealkylated series of etio-type porphyrins was observed, with $\mathrm{C}_{26}$ to $\mathrm{C}_{28}$ porphyrins predominating.

In marked contrast with the rather simple molecular weight distributions observed for nickel porphyrins from Cores 386-60 and -63 were those isolated from samples that also contained chlorins (386-43, 387-16, $-26,-35,-36,-37$, and -49$)$. The etio series again made a major contribution to the total nickel porphyrin fraction and consisted mainly of the dealkylated homologs $\left(\mathrm{C}_{30}\right.$ to $\left.\mathrm{C}_{27}\right)$. Four to seven members of the etio series were present. However, the DPEP series made a smaller contribution and only three or four homologs were observed.

The complexity of the mass spectra from these nickel porphyrin samples was increased by the occurrence of two homologous series 7 and 9 mass units distant from the corresponding nickel DPEP series number. The molecular weight distributions of these series often appear to mirror the distribution of the nickel DPEP and etio series. Lower homologs, suggesting dealkylation, have the greater peak intensities.

These peculiar metalloporphyrins have not been structurally characterized, and no interpretation has been made concerning their origin or significance. They have been observed previously in deeper core samples collected from the Black Sea and in Miocene and Cretaceous samples from Blake-Bahama Basin. Pigments with these molecular weight distributions apparently occur with chlorins and may represent a different phase of diagenesis than those of the nickel DPEP-etio series.

\section{DISCUSSION}

The data reported in this study further confirm the utility of chlorophyll degradation products as indicators of environmental parameters. For example, preservation of chlorins in sediments as old as Cretaceous is indicative of a mild thermal history. In addition, the association of vanadyl porphyrins with chlorins suggests a deviation from the expected diagenetic trend.

Depth of burial (i.e., temperature) was again shown to be a more important factor than relative geologic age in determining the degree of tetrapyrrole diagenesis. DPEP and etio nickel porphyrins were found in Albian/Aptian Cores 386-60 and -63 recovered from 915 and 937 meters depth of burial while chlorin and nickel porphyrin was present in the older but more shallow sediments of Core 387-49.

The unusual combination of early and late diagenetic products in Core 386-43 drew our attention. Although we do not fully understand the processes that lead to this combination, we can offer a few possible explanations. The association of vanadyl porphyrins with chlorins suggests that either a crude oil has entered the sediment or reworking has occurred. A third possible explanation of this unusual pigment combination is the possibility that the organic material that was deposited in Core 386-43 was different from that deposited in the other samples. In addition to the out-of-place vanadyl porphyrin was the presence of abundant high molecular weight organic material. However, Cores 386-44 and -45, 20 and 25 meters deeper, contained only small amounts of nickel porphyrin, and the high molecular weight material was not observed. In the deepest samples (Cores 386-60 and -63$)$, where nickel porphyrins were expected and found, the amount of high molecular weight material was significantly less in comparison with Core 386-43. No vanadyl porphyrins were present in any of these deeper cores.

Thus, one particular core (386-43) stands out as being a geochemical contradiction. Combined here with diagenetic products representative of the chlorin to porphyrin transition is the unexpected presence of vanadyl porphyrins, one-third as abundant as chlorins. Because vanadyl porphyrins are so thermodynamically stable, their presence is interpreted as representing a much later stage of porphyrin diagenesis.

The significance of the high degree of dealkylation observed in the total metalloporphyrin suite is not yet apparent; however, a few inferences can be made concerning individual samples. Initial "dealkylation", reactions occur in free-base porphyrins as evidenced by 
molecular weight distributions (such as for the free-base fraction, core 386-43) where m/e 476 (DPEP) is the major component and three to four lower homologs $\left(\mathrm{C}_{31}-\mathrm{C}_{28}\right)$ are present in lesser quantities. This same pattern is observed after chelation with nickel or vanadyl. This phase of "dealkylation" occurs at an early to intermediate stage of diagenesis under conditions of mild thermal stress.

Symmetrical molecular weight distributions observed for nickel porphyrins isolated from deep core samples, 386-60 and -63, are reminiscent of petroporphyrins, however, these, in contrast to the typical petroporphyrin, are dealkylated, with $\mathrm{C}_{27}-\mathrm{C}_{30}$ porphyrins being most abundant. In these samples and in petroporphyrins, symmetry suggests a nonselective dealkylation process. In contrast with petroporphyrins, only a minor fraction of the molecular weight distribution was composed of $\mathrm{C}_{33}$ (or greater) porphyrins. This finding suggests that transalkylation was minimal.

A similar explanation is offered for the altered molecular weight distribution of the vanadyl porphyrins from Core 386-43. Secondary dealkylation may have influenced the observed shift in the major peak from $\mathrm{m} / \mathrm{e} 541$ to $\mathrm{m} / \mathrm{e} 527$.

In contrast with the nearly symmetrical envelopes described above, irregular molecular weight distributions were observed for the highly nonvolatile metalloporphyrins fractions associated with chlorins. Irregularity of the envelope, produced by different trends in the individual series (i.e., one may increase towards higher molecular weight members, one may decrease, and the other may tend toward symmetry), may reflect some structural or environmental factors: (1) complexity may result from more than one set of diagenetic reactions occurring in the same time span or within different time periods (i.e., initial and secondary phases); (2) an influx of pigments with a different diagenetic history. Solution to this problem may be delayed until better characterization of the odd molecular weight series of metalloporphyrins has been made.

In this study, chlorins and nickel porphyrins were found in Upper and Lower Cretaceous sediments from the Bermuda Rise Site 387 at 415 to 787 meters. In contrasit, more deeply buried ( 874 to $937 \mathrm{~m}$ ) Lower Cretaceous sediments at Site 386 , contained only nickel porphyrins. Paradoxically, one sample of Upper Creta- ceous sediment (386-43) at 740 meters depth, contained a full range of chlorophyll degradation products: chlorins, free-base porphyrins, and both nickel and vanadyl porphyrins. Surprisingly, free-base porphyrins were not found in other chlorin-containing samples and vanadyl porphyrins were not found in the deeper core samples of Site 386. Chlorins were found in the younger (Pleistocene to Miocene) shallower (57 to $269 \mathrm{~m}$ ) samples of Site 382 located on the New England Sea Mounts.

\section{ACKNOWLEDGMENTS}

This research was supported by the Oceanography Section of the National Science Foundation, Grants DES 74-12438 AO1 and OCE 74-12438 A02.

The authors want to thank Drs. Karl S. Schorno, Phillips Petroleum Company, John Kendrick, Archie Hood, and Pierre Mommessin, Shell Development Company, for their reviews of this report.

\section{REFERENCES}

Baker, E. W., Palmer, S. E., and Huang, W. Y., 1978a. Chlorin and porphyrin geochemistry of DSDP Leg 40 sediments. In Bolli, H. M., Ryan, W. B. F., et al., Initial Reports of the Deep Sea Drilling Project, Supplement to Volumes 38, 39, 40 and 41: Washington (U. S. Government Printing Office), p. 639-648. 1978b. Early and intermediate chlorophyll diagenesis of Black Sea Sediments: Sites 379, 380, and 381. In Ross, D., Neprochnov, Y., et al., Initial Reports of the Deep Sea Drilling Project, v. 42, Part 2: Washington (U. S. Government Printing Office), p. 707-715.

, 1978c. Intermediate and late diagenetic tetrapyrrole pigments, Leg 41: Cape Verde Rise and Basin. In Lancelot, Y., Siebold, E., et al., Initial Reports of the Deep Sea Drilling Project, v. 41: Washington (U. S. Government Printing Office), p. 825-837.

1978d. Miocene and Cretaceous tetrapyrrole pigments from Leg 44, Site 391. In Benson, W. E., Sheridan, R. E., et al., Initial Reports of the Deep Sea Drilling Project, v. 44: Washington (U. S. Government Printing Office), p. 639-643.

Baker, E. W., Palmer, S. E., and Parrish, K. L., 1976. Tetrapyrrole pigments in DSDP Leg 38 sediments. In Talwani, M., Udintsev, G., et al., Initial Reports of the Deep Sea Drilling Project, v. 38: Washington (U. S. Government Printing Office), p. 785-790. 